\title{
"Libres de prejuicios, libres de mentores, dueños de sí mismos": la reorganización gremial en Mendoza durante los años de la primera posguerra (1919-1923)*
}

\author{
"Free of Prejudice, Free of Mentors, Masters of Themselves": Union \\ Reorganization in Mendoza During the First Postwar Years (1919-1923)
}

\author{
MARIANA PEREYRA \\ MATÍAS LATORRE
}

\section{Resumen}

Tras las huelgas de 1919, la Federación Obrera Provincial de Mendoza (FOPM), hasta entonces dirigida por el sindicalismo, quedó sin dirección y prácticamente desarticulada. Ante esto, hubo numerosos intentos de organización y reorganización de las diversas tendencias sindicales y de la izquierda mendocina. Este trabajo realiza una reconstrucción histórica del proceso de reorganización gremial protagonizado por los trabajadores mendocinos en los años de la primera posguerra (1919-1921) y la refundación de la FOPM a partir de entonces. Se utilizan en particular fuentes y documentación de las izquierdas mendocinas.

Palabras clave

Federación Obrera Provincial Mendocina; Reorganización gremial; Izquierdas; Federación Obrera Local Comunista; Mendoza.

\begin{abstract}
After the strikes of 1919, the Mendoza Provincial Workers Federation (FOPM), until then led by trade unionism, was left without leadership and practically dismantled. Faced with this, there were numerous attempts to organize and reorganize the various trade union and left-wing tendencies in Mendoza. This work carries out a historical reconstruction of the union reorganization process carried out by the Mendoza workers in the years of the first postwar period (19191921) and the refounding of the FOPM from then on. In particular, sources and documentation from the Mendoza lefts are used.
\end{abstract}

\section{Keywords}

Federation of Workers of the Province of Mendoza; Union reorganization; Left; Local Communist Workers Federation; Mendoza.

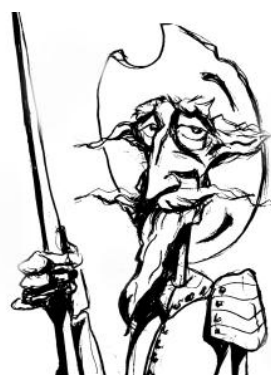

Recibido con pedido de publicación el 6 de mayo de 2021

Aceptado para su publicación el 25 de octubre de 2021

Versión definitiva recibida el 11 de noviembre de 2021

https://doi.org/10.35305/prohistoria.vi36.1521

Mariana Pereyra, Instituto de Ciencias Humanas, Sociales y Ambientales. Consejo Nacional de Investigaciones Científicas y Técnicas de Argentina, Mendoza, Argentina; e-mail: mpereyra@mendoza-conicet.gob.ar Matías Latorre, Instituto de Educación Superior 9-030, Mendoza, Argentina; e-mail: calibanesco@gmail.com

* Los autores agradecen los valiosos y minuciosos comentarios de las/os evaluadores de esta publicación y del Dr. Rodolfo Richard-Jorba y la Dra. Gabriela Scodeller, que permitieron enriquecer notablemente el presente artículo.

Esta obra se publica bajo licencia Creative Commons. Atribución-NoComercial-CompartirIgual 4.0

(cc) EY-NG-SA Internacional

Pereyra, M. y Latorre, M. “Libres de prejuicios, libres de mentores, dueños de sí mismos”: la reorganización gremial en Mendoza durante los años de la primera posguerra (1919-1923). Prohistoria, Año XXIV, 36, dic. 2021, 1-29. 


\section{Introducción}

En un contexto global marcado por las consecuencias de la Primera Guerra Mundial y el avance de las revoluciones obreras en Europa a partir de 1917, se registró un aumento de la conflictividad en Argentina que tuvo sus hitos en la "Semana Trágica" de enero de 1919, en las huelgas patagónicas y en La Forestal (Santa Fe) en 1921, entre otros. Estos acontecimientos marcaron la culminación de un proceso de ascenso de lucha y organización obrera que comenzó a declinar en los primeros años de la década del 20 y cuyas consecuencias se extendieron durante varios años, con particularidades en las diversas regiones.

En Mendoza, los trabajadores venían desarrollando experiencias de lucha desde sus orígenes a fines del siglo XIX, momento en el que se comenzaron a sentar las bases del sistema agroindustrial vitivinícola provincial. La especialización económica en la vitivinicultura y el arribo de inmigrantes fue uno de los elementos fundamentales que le dio una determinada fisonomía al mercado laboral mendocino. El oasis norte, donde se encuentra la capital, fue el área productiva más importante de la provincia, cuyas características físicas regionales permitieron que la población urbana no se disociara de la rural y, de esta manera, se estableciera un contacto permanente entre la población que se empleaba en el sector primario y la que habitaba y trabajaba en la ciudad (Cerdá, 2006). Teniendo en cuenta estos elementos, hacia 1914 los sectores más importantes que componían el mundo del trabajo provincial eran el grupo de trabajadores industriales y artesanos (13,3\%), los agrícolas y ganaderos $(12,4 \%)$, el sector de servicios $(7,8 \%)$ y el grupo denominado actividades diversas $(66,5 \%)$ en el que el mayor porcentaje lo constituían trabajadores precarios (jornaleros y sin profesión) (Richard-Jorba, 2010a).

Partiendo de lo expuesto podemos avanzar en una compresión mayor de la conflictividad obrera provincial. La historia del movimiento obrero mendocino en la década del 20 ha sido poco explorada, tanto a nivel académico ${ }^{1}$ como en la que se denomina "historia militante". ${ }^{2}$ Recientemente, algunos estudios han dado cuenta de importantes procesos de lucha a nivel sindical y político (Richard Jorba, 2020; Pereyra, 2020). Sin embargo, aún existe un vacío

\footnotetext{
${ }^{1}$ Sobre la década del 1920 hay estudios de Richard-Jorba (2020), Pereyra (2020) y Satlari (2009; 2011). Por otro lado, en general, la conflictividad obrera en las primeras décadas del siglo XX en Mendoza ha sido poco investigada. Sin embargo, hay algunas investigaciones que han realizado importantes aportes, entre las que encontramos principalmente las de Richard-Jorba (2013; 2016; entre otros), Beigel (2004), De la Vega (1997), Latorre (2019), Carminatti (2006), Silva (2012), entre otros.

2 En Mendoza, el principal referente de "Historia Militante" sobre este período es Benito Marianetti proveniente del Partido Socialista inicialmente, posteriormente del Partido Socialista Obrero y finalmente del Partido Comunista. Dos de sus principales obras sobre el movimiento obrero mendocino, Las luchas sociales en Mendoza y Mendoza, la bien plantada, si bien implican un gran aporte, no profundizan en la década del 20.
} 
que resulta fundamental llenar para poder lograr una mirada de conjunto a la historia del movimiento obrero provincial y nacional. En este sentido, la localización de la temática en la provincia no solo responde a una vacancia temática sino que, además, los aportes teórico-metodológicos sobre escalas de análisis nos permiten formular un diálogo con estudios realizados en otras regiones del país, inclusive con aquellos denominados "nacionales", a fin de problematizar los procesos formativos y las derivas asumida por la clase trabajadora desde un período y espacio local (Bohoslavsky, 2018; Andújar y Lichtmajer, 2021). Uno de los puntos fundamentales en este sentido es abordar qué sucedió con la Federación Obrera de la Provincia de Mendoza (FOPM) luego de la derrota sufrida en 1919 tras la cuarta huelga general declarada durante ese año: ¿Qué resoluciones tomaron los gremios federados? ¿Cuál fue la tendencia política más influyente en el movimiento obrero mendocino? ¿Cómo se desarrollaron las disputas entre FORA $V$ y FORA IX en el movimiento obrero provincial? ¿Cómo actuaron los trabajadores mendocinos en las huelgas que se dieron después de 1919?

Basándonos en cuatro periódicos de las izquierdas mendocinas ( $E l$ Socialista, Pensamiento Nuevo, La Voz del Gremio y Surco Proletario) este artículo realiza una reconstrucción histórica de la temática planteada. ${ }^{3}$ De esta forma, no solo mostraremos la especificidad de la FOPM, sino que también observamos la importancia de las huelgas en el proceso de organización y reorganización de la misma. Asimismo, este trabajo muestra la importancia del elemento subjetivo en este caso las izquierdas mendocinas- en la constitución del movimiento obrero provincial.

Siguiendo los aportes teórico-metodológicos del historiador Nicolás Iñigo Carrera $(2004 ; 2017 ; 2019)$ consideramos que las huelgas constituyen una de las formas de confrontación más importantes debido a que en las mismas se manifiesta potencialmente la clase obrera como conjunto y esto determina, en gran parte, la forma de organización de la misma. Además, desde la perspectiva teórica de Hernán Camarero $(2007 ;$ 2017) y otros/as, entendemos que el elemento subjetivo es fundamental para comprender la dinámica del movimiento obrero, por lo cual también abordamos incipientemente las disputas entre las corrientes de las izquierdas que intervenían en el movimiento obrero local en ese momento.

Por otro lado, además de aportar a una vacancia temática, iniciamos un debate con las visiones que plantean que las corrientes anarquistas tuvieron un alcance limitado a la provincia de Buenos Aires, teniendo un peso casi

\footnotetext{
${ }^{3}$ La elección de estos periódicos se fundamenta en que en ellos se despliega en profundidad el proceso de reorganización gremial de la provincia. Asimismo, las prensas de las izquierdas y de gremios abordadas en este trabajo son las únicas disponibles (hasta el momento) sobre este período en la Hemeroteca de la Biblioteca Pública General San Martín.
} 
irrelevante en las provincias (Suriano, 2001), mostrando que en la década del 20 el anarquismo de la FORA Comunista se encontraba dirigiendo la FOPM después de una larga disputa con el sindicalismo y el socialismo. Este elemento implica también aportar desde la periferia a las características que tuvieron las izquierdas en esta etapa, estudiándolas en una de las provincias del interior del país, Mendoza. El trabajo aporta una mirada a las tendencias de conjunto, destacando una de ellas, la anarquista.

\section{Breve reseña de los acontecimientos nacionales durante 1919}

A nivel nacional, una vez finalizada "La Semana Trágica" en enero de 1919, hito en la historia del movimiento obrero argentino, no se registró un retroceso en las luchas sindicales, ya que en los primeros seis meses de 1919 se produjeron más de 50 huelgas que movilizaron a alrededor de 10.000 obreros (Falcón y Montserrat, 2000). Este clima reavivó a las fuerzas conservadoras, lo cual implicó que la Liga Patriótica se radicalizara, por lo que el gobierno aplicó nuevamente una serie de leyes, como la Ley de Residencia y de Defensa Social para, de esta forma, calmar momentáneamente a la derecha más extrema.

A nivel sindical, desde la Revolución Rusa, se dieron fuertes debates entre las diferentes tendencias que surgieron. Dentro del anarquismo ${ }^{4}$ había surgido la fracción "anarco-bolchevique"; 5 el socialismo había tenido una escisión por la cual apareció el Partido Socialista Internacional y hacia 1921 se fueron parte de los que eran favorables a adherir a la Internacional Comunista; los sindicalistas $^{6}$ volvieron a adquirir durante algún tiempo su carácter

\footnotetext{
${ }^{4}$ Hacia 1920 el anarquismo ya se encontraba dividido entre el sector vinculado a la FORA V y al periódico La Protesta y aquellos relacionados al periódico La Antorcha. A mediados de la década del 20 surgieron los autodenominados "Anarquistas expropiadores" (Anapios, 2007). Según Camarero (2017), además de estas publicaciones se le sumaron Ideas (La Plata) y Pampa Libre (La Pampa), con otros sindicatos y agrupaciones que ya estaban fuera de la FORA.

${ }^{5}$ Los anarco-bolcheviques fueron expulsados de la FORA en 1921 (Anapios, 2007). Según Camarero (2017), una tercera variante del anarquismo nació en Rosario en 1913 alrededor del periódico La Rebelión que estaba dirigido por Enrique García Thomas, quien fue simpatizante de la Revolución Rusa. En 1918 se fusionó con núcleos que tenían la misma posición y se creó la Federación Anarquista y se fundaron los periódicos Bandera Roja y Diarios de la Mañana. Los principales referentes de esta tendencia, además de García Thomas fueron Atilio Biondi, Hermenegildo Rosales, Santiago Locascio, Sebastián Ferrer, Elías Castelnuovo y Julio R. Barcos. El dato sobresaliente es que desde fines de 1919 estos grupos controlaron la dirección de la FORA V que, en sus resoluciones del congreso de 1920, expresó su solidaridad con la Revolución Rusa. Luego de 1921 se consolidó la tendencia mayoritaria al rechazo a la Revolución Rusa, sobre todo después de los sucesos de Kronstad.

${ }^{6}$ Entre los estudios sobre las izquierdas en Argentina, el sindicalismo ha sido poco estudiado en relación al resto de las corrientes -anarquismo, socialismo, comunismo (Caruso, 2016). Sin embargo, según la autora en los últimos años han surgido líneas de investigación que avanzan sobre algunos debates y experiencias de esta corriente. En este sentido destacamos los trabajos
} 
revolucionario (Falcón y Montserrat, 2000). Estos elementos nos muestran un contexto en donde el movimiento obrero se encontraba atravesado por importantes debates que tuvieron un gran impacto en los gremios que, en general, estaban dirigidos por estas tendencias.

Por otro lado, la relación entre el gobierno de Yrigoyen y la Federación Obrera Regional Argentina del $9^{\circ}$ Congreso (FORA IX, Sindicalista) ya no fue tan cordial como en años anteriores, debido tanto a los proyectos de legislación que promovía el gobierno -y que para los sindicalistas podrían implicar un avance contra las libertades y derechos conquistados por los trabajadorescomo a las represiones que se dieron en diferentes huelgas. En este contexto de disminución de la capacidad de movilización del movimiento obrero, las filas de la FORA IX comenzaron a decrecer. ${ }^{7}$ A su vez, internamente se produjeron fuertes disensos (Falcón y Montserrat, 2000). A este último elemento debemos sumarle el hecho de que, en determinados momentos, la FORA IX fue cuestionada por la forma en que actuó en determinados conflictos y esto fue lo que, en algunos casos, determinó su decaimiento o pérdida de influencia en el movimiento obrero. Esto fue lo que sucedió en Mendoza a partir de la segunda huelga general declarada por la FOPM en solidaridad con el sindicato del magisterio, Maestros Unidos (MU), en octubre de 1919.

\section{La situación en Mendoza y la FOPM hacia 1919}

Antes de las importantes huelgas de 1919, el movimiento obrero mendocino había construido una larga tradición de lucha que le dio desde un principio una fisonomía muy combativa (Pereyra, 2020).

Después de atravesar un período en el que los trabajadores de la provincia desarrollaron conflictos de resistencia individual (fines del siglo XIX), a principios del siglo XX aproximadamente, éstos comenzaron a organizarse de manera colectiva, luchando mayormente por mejorar sus condiciones de trabajo, por salarios, en rechazo a las normas estatales y, en algunos casos por demandas relacionadas con posiciones políticas e ideológicas y en solidaridad con otras huelgas (Richard-Jorba, 2010b). ${ }^{8}$

de Alejandro Belkin (2015; 2018; 2021), Cristian Aquino (2015; 2017) y Laura Caruso (2016), entre otros/as.

${ }^{7}$ Según Falcón y Montserrat (2000) en 1920 la FORA IX tenía 70.000 afiliados cotizantes mensuales, mientras que cuando se fundó la Unión Sindical Argentina (USA) poseía alrededor de 20.000 adherentes.

${ }^{8}$ Satlari (2009) plantea que, hacia fines del siglo XIX, el anarquismo fue una de las primeras corrientes políticas que llegaron a Mendoza, de la mano de los inmigrantes. El Partido Socialista se organizó en la provincia en 1900. 
Hacia 1912 se dieron huelgas muy importantes de ferroviarios, en las que los obreros mendocinos tuvieron un rol destacado. En 1914, la desocupación y los bajos salarios determinaron, en gran parte, el desarrollo de algunos conflictos que fueron reprimidos por la policía. A fines de 1917, los ferroviarios nuevamente fueron a la huelga. Ésta fue brutalmente reprimida por el gobierno de Francisco Álvarez, dejando como saldo dos obreras asesinadas y decenas de heridos.

En cuanto a la organización sindical, la FOPM aglutinó a la mayoría de los gremios de la provincia (Pereyra, 2020). Ésta, según El Socialista, órgano oficial del Partido Socialista de Mendoza (PS) se conformó en 1918, tras la realización del Congreso Obrero del 29 y 30 de junio de ese año, resultando elegidos Cayetano Pessina (secretario general), Pedro González (secretario de actas), José V. García (tesorero) y un delegado por cada sociedad adherente. ${ }^{9}$

El nacimiento de la FOPM se dio en el mismo año en que José Néstor Lencinas ${ }^{10}$ arribó al gobierno provincial. El Lencinismo (movimiento que tomó esta denominación a partir del nombre del gobernador) fue un fenómeno político que formó parte del avance democrático de los primeros años del radicalismo y lo radicalizó. La influencia que ejerció este movimiento sobre la clase obrera mendocina fue muy importante. En este sentido, implementó leyes protectoras para los trabajadores (mejores ingresos y condiciones de trabajo) y los sectores populares. Por otro lado, de la misma forma que el Yrigoyenismo, estableció una relación ambigua con el movimiento obrero, intermediando favorablemente en algunos casos y, en otros, mediante la utilización de coerción y represión legal e ilegal (Richard-Jorba, 2013). ${ }^{11}$ El período de estudio en la provincia, si bien comienza durante el primer gobierno de J. N. Lencinas, también abarca períodos de intervenciones federales con alternancia de gobiernos provinciales, por lo cual hubo momentos en los cuales los trabajadores gozaron en general de mayores libertades democráticas formales y períodos en los cuales la represión fue más explícita. ${ }^{12}$

\footnotetext{
${ }^{9}$ El Socialista (ES), 6/10/1918.

${ }^{10}$ Gobernador entre marzo de 1918 y enero de 1920 (año en el que falleció).

${ }^{11}$ Las principales legislaciones obreras fueron: Ley 732 (estableció la jornada de ocho horas y fijó un sueldo mínimo, que solo se aplicó al sector público durante su gobierno); y Ley 731 (creó la Inspección General del Trabajo y regulaba el trabajo de mujeres y niños de hasta 14 años), que comenzó a implementarse durante el gobierno de Carlos Washington Lencinas a principios de la década del 20 (Luis, 2017).

${ }^{12}$ El primer gobierno de J. N. Lencinas comenzó el 6 de marzo de 1918 y finalizó el 17 de febrero de 1919, siendo interrumpido por dos intervenciones federales (Tomás de Veyga, 17 febrero 1919/12 abril 1919; Perfecto Araya, 12 abril 1919/25 julio 1919). Posteriormente, J. N. Lencinas volvió a gobernar desde el 25 de julio de 1919 hasta su fallecimiento (20 de enero de 1920), donde fue sucedido por Ricardo Baez, quien gobernó entre el 20 de enero y el 3 de septiembre de 1920. A este gobierno le siguió la intervención federal de Eudoro Vargas Gómez (3 de
} 
Múltiples, en extensión e intensidad, fueron los conflictos obreros que se desarrollaron durante el corto gobierno de J. N. Lencinas (Richard-Jorba, 2013a, 2013b, 2020; Carminatti, 2006; Silva, 2012). Sin embargo, destacamos el largo conflicto que mantuvo el gremio del magisterio en 1919 que determinó el desarrollo de dos importantes huelgas generales declaradas por la FOPM en solidaridad con las maestras, constituyendo de esta forma, un momento bisagra para la historia del movimiento obrero provincial. ${ }^{13}$ La última de estas huelgas finalizó en octubre y representó una dura derrota para las y los trabajadores que protagonizaron un conflicto que fue adquiriendo un carácter cada vez más violento, incluyendo enfrentamientos entre obreros y fuerzas de seguridad, sabotajes en el servicio eléctrico, heridos, un muerto, detenciones, secuestro de dirigentes obreros, deportaciones, abandono de obreros en el desierto, y un terror generalizado para la clase trabajadora y el conjunto de la población.

Este conflicto estuvo dirigido por la FOPM, que a su vez estaba adherida a la FORA IX. ${ }^{14}$ Previamente a la mencionada huelga general, la FOPM era una poderosa organización que poseía aproximadamente 55 gremios en su interior, según se constató en las prensas socialista y anarquista de Pensamiento Nuevo, ${ }^{15}$ pero una vez finalizada la misma, casi todos los gremios la abandonaron. ${ }^{16}$ La derrota de la huelga fue atribuida a la dirección sindicalista ${ }^{17}$ particularmente a los delegados que la FORA IX había enviado para intervenir en la misma: ${ }^{18}$

septiembre de 1920/4 de febrero de 1922). Finalmente, Carlos Washington Lencinas (Hijo de J. N. Lencinas) fue gobernador desde el 4 de febrero de 1922 hasta el 9 de octubre de 1924.

13 Para mayor desarrollo de este conflicto ver De la Vega (1997); Satlari (2011); Richard Jorba (2014); Latorre (2019), entre otros.

${ }^{14}$ El sindicalismo tuvo una gran influencia en la provincia hasta 1919. En su gran expansión nacional entre 1915 y 1918 pasó de tener 51 a 350 gremios con más de 400.000 afiliados, de los cuales un $4 \%$ estaba en Mendoza (Richard-Jorba, 2020).

${ }^{15}$ Pensamiento Nuevo $(P N)$ fue un periódico de tendencia anarquista cercana a la FORA V hasta 1921, momento en el cual pasa a formar parte plenamente de esta federación. Este periódico vuelve a aparecer en enero de 1920, después de 10 años de no haberse editado. Sus principales referentes fueron Cupertino Gris y José Pruneda. En su número del 1-1-1920 extiende una lista de 55 gremios federados. Para el II Congreso de la FOPM celebrado durante el mes de abril de 1919 los socialistas calculaban que la participación de los gremios alcanzaba a 40 gremios (ES, $1 / 5 / 1919)$, y crecieron en número con posterioridad.

16 PN el 1/2/1920, dio una lista de los gremios que se separaron de la FORA IX a la que denominaban "FORA Camaleónica", estos sumaban un total de 18 hasta esa fecha: Viticultores de Villa Atuel; Conductores de carros y carretelas; Contratistas de Cuadro Nacional; Carpinteros, ciudad; Unión general de mozos, cocineros y pasteleros; Albañiles; Oficiales peluqueros; Telegrafistas y empleados postales; Unión carniceros; Viticultores de Rivadavia; Viticultores de Godoy Cruz; Unión pintores; Metalúrgicos; Maestros Unidos; Artes gráficas; Conductores de vehículos; Obreros talabarteros y Obreros fideeros.

${ }^{17}$ Es necesario destacar que el Socialismo tuvo roles de dirección en este proceso, sobre todo por la importante participación de militantes obreros en el Consejo Federal de la FOPM y la permanente colaboración con Maestros Unidos. Véase ES, 22/11/1919.

${ }^{18}$ La FORA IX, durante ese período, tuvo una política de enviar representantes de la federación 
Bartolomé Senra Pacheco (subsecretario de la FORA IX), Francisco J. García (secretario general de la Federación Obrera Marítima) y Luis Lotito (obrero gráfico y delegado de la federación sindicalista). ${ }^{19}$ Esta federación quedó totalmente desprestigiada frente a los trabajadores mendocinos, ya que se había comprometido a secundar la huelga provincial con una nacional que nunca se realizó. El Socialista dio a conocer una parte del manifiesto de la FOPM en sus páginas unos días después de finalizado el conflicto:

“Este manifiesto debió ser lanzado a la publicidad al día siguiente de terminada la huelga general, pero la Junta Deliberativa de la Federación no pudo reunirse debido a las persecuciones policiales [...]. Además, ninguna imprenta se habría aventurado a imprimirla en momentos de inseguridad puesto que las garantías individuales habían desaparecido, predominando en todos los espíritus libres la indignación y en los pusilánimes el miedo ante el terror policial desencadenado contra los trabajadores.

Requerido Senra Pacheco por algunos delegados sobre la actitud que asumiría la FORA, frente al conflicto Mendocino, dijo que ésta no podría comprometer sus fuerzas en un movimiento que pretendía levantar a tres cadáveres como lo eran "Maestros Unidos", Toneleros y Telefonistas. A esto le replicó un delegado que si así era, Senra Pacheco había venido a Mendoza a enterrarlos. [...]

La desmoralización de los gremios no tardó en producirse; desmoralización producida por las declaraciones de Pacheco. Enterados los gremios, empezó la desconfianza.

Al día siguiente del rechazo de la proposición de arreglo traída por Senra Pacheco, la policía dio comienzo a las persecuciones. El local de empleados de comercio fue rodeado por un grueso pelotón de soldados del escuadrón y los concurrentes que, pasaban de 200, fueron conducidos al departamento de policía, en medio de insultos y empellones. Muchas maestras fueron también detenidas [...]. Los locales gremiales fueron clausurados por la policía y por las calles se molestaba a los viandantes que a cada paso eran amenazados por la soldadesca armada y que en grupos ocupaba la mayor parte de las bocacalles como si estuviéramos en estado de guerra.

de gira a las provincias para organizar a los trabajadores, considerando que el movimiento obrero del interior no poseía organizaciones fuertes (Leyes, 2009; Díaz, 2014).

${ }^{19} P N, 1 / 1 / 1920$. 
La junta deliberativa hubo de reunirse en sitios reservados, pues fuerzas armadas vigilaban el local.

Mientras tanto, el delegado Senra Pacheco permanecía inmutable, mostrando una reserva a todo trance cada vez que los delegados le exigían categóricas declaraciones sobre la actitud de la Fora, ya que ésta había prometido su apoyo material cuando los acontecimientos lo exigieran [...].

[Pacheco] pretendía convencer a los miembros de la junta con telegramas y mentiras tan burdas como groseras. [...] Pesa sobre nosotros la vergüenza de una traición sin precedentes en la historia proletaria argentina [...].

Tengamos muy presente, trabajadores, esta lección recibida. Ya no os quepa duda sobre la existencia de un núcleo de mercenarios en la F.O.R.A. Sus hechos nebulosos primero y abiertamente opuestos a nuestra causa, después, hablan demasiado claro. Parece que hay mucho de podrido en dicha institución y toca a los obreros mendocinos decidir lo más pronto la actitud que cabe adoptar antes que tengamos que lamentar nuevas vergüenzas". ${ }^{20}$

Como es de suponer, el resultado del conflicto acarreó graves consecuencias a la FOPM que siguió funcionando con pocos gremios en su interior, ya que varios de ellos, al desafiliarse de la FORA, también lo hicieron de la federación provincial cuya dirección era sindicalista. Varios de los miembros del Consejo Federal (CF) de la FOPM eran representantes de la FORA IX (Lotito, entre otros), ${ }^{21}$ por lo cual hubo un vacío en la dirección y orientación en la organización obrera. ${ }^{22}$ El Secretario General de la FOPM, después de octubre de 1919, fue el socialista Grant Carrión (secretario general del Centro Empleados de Comercio). Una de las primeras resoluciones que tomó la federación provincial bajo esta dirección, fue suspender toda relación oficial con el CF de la FORA IX hasta que los gremios federados de la provincia se reunieran y acordaran qué actitud tomar. ${ }^{23}$

Todo este período, desde la finalización de la huelga a mediados de octubre, estuvo marcado por numerosos intentos de reorganización y

\footnotetext{
${ }^{20} E S, 26 / 10 / 1919$.

${ }^{21} E S, 12 / 10 / 1919$.

${ }^{22}$ El 17 de abril de 1919 se había realizado el Segundo Congreso de la FOPM para elegir a los miembros del Consejo Federal de la misma. En éste, fue elegido Pessina como secretario general (ES, 1/5/1919). Se puede suponer que la orientación política de Pessina era sindicalista porque la mayoría de los miembros propuestos para integrar el CF respondían a esta tendencia, entre ellos Luis Lotito.

${ }^{23} E S, 16 / 11 / 1919$.
} 
fortalecimiento de la FOPM, así como también tentativas de unidad con federaciones y sindicatos de otras provincias, ${ }^{24}$ acercamientos al socialismo, al sindicalismo y a la FORA V y demás tendencias del anarquismo. Es decir, todo el proceso de reorganización del movimiento obrero mendocino estuvo cruzado por la lucha tendencial entre estas corrientes políticas.

El $1^{\circ}$ enero de 1920 apareció el primer número de la segunda época del periódico quincenal $P N$. Este órgano de orientación anarquista reivindicaba a la FORA $\mathrm{V}$ y bregaba por la organización de los obreros mendocinos en la misma. ${ }^{25}$ En sus primeros números dedicaba sus páginas, sobre todo, a la lucha política contra sindicalistas y socialistas, haciendo permanente referencia a la derrota de la huelga general declarada en solidaridad con las maestras de fines de 1919. Los socialistas advirtieron inmediatamente el desembarco de los anarquistas de $P N$, planteando que el contexto de debilidad del movimiento obrero provincial había dejado las puertas abiertas a la acción del anarquismo y exhortaban: "iAlerta, trabajadores! Los anarquistas se mueven, las organizaciones gremiales peligran". ${ }^{26}$ Su línea argumental continuaba indicando la infiltración de libertarios en los gremios para embarcarlos en una "tendencia ideológica o sectaria" propiciando la destrucción y las divisiones. Puesto que, además, para el socialismo local "los gremios deben gozar de entera independencia", denunciaban que su presencia destruiría "las organizaciones obreras en aras de su ambición, de su egoísmo o de la estúpida ingenuidad de algunos cándidos que todavía hablan de la "gimnasia revolucionaria". ${ }^{27}$

Entre los planes más inmediatos del anarquismo organizado en $P N$, se hallaba la convocatoria a un Congreso Obrero Provincial para reunificar al movimiento obrero y darle una nueva orientación. ${ }^{28}$ En simultáneo, arribaron dos delegados de la FORA $\mathrm{V}$ a la provincia, con el firme propósito de organizar a los trabajadores mendocinos desafiliados de la FORA IX y a los gremios autónomos, además de propagar la idea. A pesar de sus escasos movimientos, la FOPM había continuado en actividad, aunque estos movimientos desestabilizaron aún más a su endeble dirección.

\footnotetext{
${ }^{24}$ Una circular de la FOPM con fecha 24 de octubre de 1919, dirigiéndose a la Federación Obrera de Rosario, planteaba la convocatoria con carácter urgente a un Congreso Extraordinario de todos los sindicatos del país; ES, 21/12/1919.

${ }^{25} P N, 1 / 2 / 1920$.

${ }^{26} E S, 11 / 1 / 1920$.

${ }^{27} E S, 11 / 1 / 1920$

${ }^{28} P N, 1 / 2 / 1920$.
} 


\section{La Comisión Pro Congreso Obrero y el Congreso del 4 de julio de 1920}

Para el mes de abril de 1920 se conformó una Comisión Pro Congreso Obrero, ${ }^{29}$ cuyos integrantes fueron elegidos en una reunión de delegados de diversos gremios provinciales para conformar una federación que respondiera "a los deseos de los trabajadores $\mathrm{y}$, por lo tanto, merezca la confianza de los mismos". ${ }^{30}$ El organismo aglutinó a representantes gremiales de diversas tendencias y, por ende, se destacó por una composición heterogénea. El objetivo de reunificar al movimiento obrero, encarnado en la comisión, disentía con un contexto de marcada dispersión, que dio lugar a la lucha política entre las principales tendencias de la izquierda mendocina: anarquistas, socialistas y sindicalistas. Asimismo, inferimos que, a partir de su formación, la Comisión o Comité tuvo la función principal de organizar a los gremios provinciales desplazando a la escuálida FOPM la cual, si bien continuó existiendo por un tiempo, ya no le cupo el rol de dirección. ${ }^{31}$

Durante las primeras reuniones realizadas por la Comisión se resolvió confeccionar un manifiesto convocando a los trabajadores a organizarse en sus gremios e invitándolos a concurrir al próximo Congreso Obrero. Otro de los temas abordados, refirió a la forma de organización y los fines que debería asumir la nueva FOPM. Uno de los puntos más sensibles se dio en torno al modo en que deberían organizarse los obreros rurales e industriales. Los anarquistas de $P N$ manifestaron que creían oportuno formar una Federación Vitivinícola que se compondría de toneleros, contratistas de viña, carreros y trabajadores de bodega y de viña en general, y a su vez formar una Federación Obrera Local (FOL) que nucleara a los principales sindicatos de la capital provincial (industriales, de servicios, etc.). Ambas federaciones, conformarían la nueva FOPM. También surgieron rivalidades sobre los métodos de lucha que se daría la federación. El centro de la discusión giró en torno a la acción directa. Además, dieron comienzo al debate sobre la conveniencia o no de invitar a las dos FORA -Comunista y Sindicalista- al Congreso Provincial cuya fecha, inicialmente se fijó para el 1 de junio de $1920 .^{32}$

\footnotetext{
${ }^{29}$ En esta comisión participaban delegados de diversos gremios, entre ellos Angélica Mendoza por Maestros Unidos, miembro del Partido Comunista desde 1920 hasta 1925 (véase Camarero, 2007: 25 y Becerra, 2019: 48). Sin embargo, en sus intervenciones públicas constatadas en las prensas pesquisadas no hay referencias a su militancia político partidaria, más bien, reflejaba una posición de corte sindicalista tal cual se desprende de los estatutos de MU.

${ }^{30} P N, 20 / 4 / 1920$

${ }^{31} \mathrm{Si}$ bien no ha sido posible establecer el momento exacto de la desaparición de la FOPM, el socialismo mendocino en el informe elaborado por la Junta Ejecutiva de la Federación Socialista Mendocina y presentado al IV Congreso Ordinario Provincial del partido, daba cuenta de su eclipse durante el transcurso del año 1920 vinculando su derrotero a la represión desatada por el gobierno provincial durante los sucesos de octubre de 1919; ES, 24/12/1920.

${ }^{32}$ PN, 20/4/1920.
} 
Lo observado hasta el momento permite divisar cómo, no obstante la derrota de 1919, los trabajadores mendocinos insistían en propiciar instancias de organización y, si bien esta Comisión representó un momento de transición hacia otro organismo, implicó que el movimiento obrero desarrollara instancias de debate programático, organizativo, de métodos de lucha y balance sobre lo sucedido con la anterior dirección de la FOPM y el devenir de la futura organización.

Al mes siguiente de la fecha propuesta para el Congreso Obrero, se habló de la existencia de la FOL. Su aparición fue advertida por los socialistas del siguiente modo:

"[H]ay un grupito que ha logrado introducirse dentro de las organizaciones que brega por la formación de Federaciones Locales, es decir federaciones que no abarcarán sino ciertos gremios dentro de una zona limitada de la provincia. [...] Nadie ignora los esfuerzos del quintismo, de los anarquistas, por producir una división en el movimiento obrero, tratando por todos los medios de hacer separar los gremios de sus respectivas federaciones para hacerlos adherir a su cantado quinto congreso". ${ }^{33}$

Los pensanovistas, al contrario de los socialistas, saludaron a la naciente FOL e inclusive encomendaron a Angélica Mendoza (miembro de MU y de la Comisión Pro Congreso Obrero) a que diera cuenta de su existencia, ya que en una asamblea de albañiles a la que concurrió la había omitido, por lo cual deducimos que un importante sector de la Comisión no estaba a favor de la conformación de esta federación. ${ }^{34}$

Curiosamente, anarquistas y socialistas coincidieron, desde diferentes posiciones, sobre el mal funcionamiento del Comité y sobre el contenido plasmado en el proyecto de organización que presentaron ante los gremios y que debía servir de base para ordenar los debates del próximo Congreso. Si los pensanovistas y el gremio de repartidores de pan $^{35}$ planteaban que los miembros del comité demostraban poca preparación teórica, ya que el programa presentado refería literalmente a un "comunismo orgánico", ${ }^{36}$ desde las páginas

\footnotetext{
${ }^{33}$ ES, 9/5/1920.

${ }^{34} P N, 1 / 5 / 1920$

35 "Entre las varias reformas hechas a las citadas bases, los repartidores de pan decidieron suprimir la frase del "comunismo orgánico" aduciendo "que ni el mismo que lo propuso sabría definírnoslo". Y continuaban afirmando, "los trabajadores [...] queremos el comunismo libre; y por eso el gremio repartidores propone el comunismo anárquico, interpretando el verdadero sentido de la palabra anárquico, qué significa libre; $P N, 20 / 5 / 1920$.

36 “La comisión [...] comenzó ofreciéndonos un 'comunismo orgánico' que nos ha dejado patidifusos pues nuestra escasa inteligencia no nos ha permitido columbrar cuál sea su
} 
de ES se dispusieron a desenmascarar ante los trabajadores mendocinos los fines de un programa, al que caracterizaron peyorativamente como: "Programa anárquico-sindicalista para los gremios obreros de Mendoza". ${ }^{37}$

Los obreros gráficos solicitaron que se pospusiera la fecha de realización del Congreso, aduciendo el poco tiempo de debate que tendrían los sindicatos para revisar profundamente las bases presentadas por la Comisión. El protagonismo del gremio gráfico se tornó evidente, ya que el pedido de posponer la fecha de realización del Congreso fue acompañado de un "Contraproyecto de bases para la constitución de la Federación Obrera de Cuyo" a ser debatido en el Congreso Obrero Provincial. En términos generales, la propuesta presentada se anclaba fuertemente en varios de los postulados del anarquismo quintista. Desde $P N$, reafirmaron los planteos realizados por los gráficos y avanzaron en definiciones libertarias tales como la abolición del capitalismo, del Estado, privilegios y castas; y la transformación social en la sociedad comunista libre, la unión de los trabajadores del campo e industria en sindicatos de oficios varios y federaciones locales, comarcales o provinciales. Además, momentáneamente simpatizando con la Revolución Rusa, propusieron la dictadura de proletariado mediante la toma de los medios de producción y la organización comunista de los trabajadores, la implantación del régimen agrario y la necesidad de exponer libremente las ideas libertarias en los sindicatos adheridos. Todos estos objetivos se lograrían a través de la acción directa. $^{38}$

La tendencia anarquista fue ganando posiciones cada vez más firmes en la Comisión, y nuevamente los socialistas expresaron su alerta a los trabajadores. Convocaron a los afiliados desde las páginas de ES a combatir y rechazar de plano la "tendencia política anárquico-sindicalista" con la que se pretendía embanderar a los gremios provinciales. Se pronunciaron en contra de la acción directa, boicots y sabotajes como métodos de lucha inútiles y contraproducentes para la clase trabajadora. Y otro tanto dedicaron a denostar la huelga general, que, desde octubre de 1919, había quedado cuestionada en su eficacia por muchos gremios. ${ }^{39}$

En la última sesión de la Comisión Pro Congreso Obrero se repartió el programa de discusiones para el congreso y se invitó a las federaciones

finalidad. Buscamos inútilmente en su articulado la explicación que deseábamos y en vez de encontrarla tropezamos con nuevos enigmas y renunciamos por último a saber lo que 'comunismo orgánico' significa"; $P N, 20 / 5 / 1920$.

${ }^{37} E S, 16 / 5 / 1920$.

${ }^{38} P N, 5 / 6 / 1920$.

${ }^{39}$ ES, 16/5/1920. Richard-Jorba (2014, 2020) plantea que hacia 1919 la FOPM sufría un gran desgaste por el permanente empleo de la huelga general durante ese año, que había comenzado con la huelga en enero de los tranviarios, seguida por la de toneleros, telefónicos y contratistas de viña. 
autónomas $^{40}$ a que enviaran delegaciones para asistir; además, se invitó a las federaciones regionales comunista y novenaria. Varios gremios de la campaña ${ }^{41}$ enviaron una nota a la Comisión amenazando con no asistir al Congreso si no se invitaba a los delegados expulsados por traicionar el movimiento en 1919: A. Reyes, P. Quevedo, J. Sola, F. Velasco, Senra Pacheco, Francisco J. García y a José V. García y Luis Lotito. ${ }^{42}$ Consideraban que su presencia era fundamental para esclarecer "ciertos puntos oscuros" relacionados con la huelga general provincial de octubre de 1919, en vista de que estos puntos sólo se podrían aclarar estando presentes las personas antes citadas. ${ }^{43}$ Sin embargo, no se llegó a una resolución pues la sesión fue levantada en medio de gritos por parte de los presentes. ${ }^{44}$ La petición fue repudiada por $P N$, quienes denunciaron intentos del PS y sindicalistas de boicotear el Congreso; mientras que la Comisión decidió no dar lugar a la misma y, por lo tanto, el Congreso sesionaría sin la presencia mayoritaria de los gremios pertenecientes al ámbito de la campaña. La fuerte rivalidad entre las tendencias políticas fue prevista por $P N$. Aún así, desde las filas pensanovistas bregaron en algunas de sus notas por la unidad gremial, fundamentalmente con los socialistas.

\section{Creación de la Federación Obrera Local Comunista}

Finalmente, el Congreso Obrero se realizó ${ }^{45}$ el 4 de julio de 1920, aunque la unificación y refundación de la FOPM no fue posible. La ausencia de los gremios de la campaña bloqueó el objetivo principal del Congreso y los ácratas locales acusaron a los sindicalistas -fundamentalmente a Senra Pacheco- de la maniobra consistente en cercenar la participación de los delegados sindicalistas regionales al congreso, lo cual provocó que dichos gremios no asistieran. Sin embargo, las organizaciones obreras de la capital resolvieron formar la Federación Local y continuar con medidas de propaganda entre los gremios de la campaña "para que elimine a todos los elementos malsanos que hoy detentan su representación y pueda formarse la FOP" ${ }^{46}$ La resolución más resonante del Congreso, fue la referida a los fines aceptados por la nueva federación:

\footnotetext{
${ }^{40}$ En las prensas no se especifica cuáles o cuántas eran estas federaciones autónomas.

${ }^{41}$ El requerimiento fue firmado por la Cosmopolita de Trabajadores de Maipú y Godoy Cruz. Los gremios Viticultores de Maipú, Godoy Cruz, Luján, Guaymallén, San Martín y la Unión Obrera del Algarrobal.

${ }^{42}$ Lotito y otros nombrados habían sido expulsados según las resoluciones tomadas por sus propios gremios luego de la huelga general de octubre de 1919.

${ }^{43}$ ES, 4/7/1920.

44 PN, 4/7/1920.

${ }^{45}$ El Congreso sesionó entre los días 4 y 8 de julio.

${ }^{46}$ La Voz del Gremio (LVG), 20/7/1920. Para un análisis sobre este órgano oficial de la Unión General de Mozos y anexos, de tendencia anarquista, véase Satlari (2013).
} 
"Al aceptar el congreso como finalidad el comunismo libre, ha triunfado la tendencia única que ha de traer para los trabajadores días de bonanza en las luchas a emprender; ya no será posible que los eternos mistificadores del verdadero sentido que tiene la lucha de clases ingresen en los sindicatos con fines de servir desde allí a políticos y camaleones, la luz de la verdad podrá derramarse por doquier y los trabajadores podrán con facilidad eliminar de su seno a tanto sinvergüenza que hasta hoy ha militado en las organizaciones, para terminar después en candidatos políticos de partidos que se dicen obreros y que no son sino vulgares vividores a costa de la ignorancia que hasta hoy venía pesando sobre la clase trabajadora". 47

Por lo tanto, sin la presencia de representantes sindicalistas ni socialistas, se consolidó una nueva Federación Obrera Local Comunista (FOLC) - en referencia al comunismo anárquico- con un programa que rescataba las ideas anarquistas planteadas previamente y gran parte de las bases propuestas por los obreros gráficos. La dirección de esta federación también fue anarquista. ${ }^{48}$ Al Congreso asistieron 17 gremios de los cuales, en un primer momento, 11 formaron la FOLC, y posteriormente se adhirieron 3 más. En San Rafael también se conformó una FOLC sobre las mismas bases. ${ }^{49}$ Para los socialistas esta federación solo se basaba en el personalismo de uno de sus dirigentes y, a su vez, fundador de $P N$, Cupertino Gris. ${ }^{50}$

Si bien la FOLC adhirió a los principios del comunismo anárquico, no resolvió la afiliación a la FORA V. Entre fines de septiembre y principios de octubre de 1920 se llevó adelante en Buenos Aires el $1^{\circ}$ Congreso Extraordinario de la FORA V en el cual se expresó la solidaridad con la Revolución Rusa. En este Congreso se aprobó el agregado de "comunista" a la FORA para diferenciarla de la FORA novenaria. ${ }^{51}$ En este sentido, el 30 de agosto de 1920 se reunió el Consejo Federal de la FOLC que discutió, entre otras cosas, el asunto del próximo congreso de la FORA Comunista, resolviendo mandar un delegado por la federación sin necesidad de que fuera tratado por los sindicatos. ${ }^{52} \mathrm{El}$

\footnotetext{
${ }^{47} L V G, 20 / 7 / 1920$.

${ }^{48}$ Se desconocen los nombres específicos de los miembros del Consejo Federal de la FOLC. Sin embargo, en el obituario de Cupertino Gris (fundador de $P N$ ) publicado el 17 de octubre de 1938 en el Diario Los Andes se describe que éste fue secretario de la FOLC.

${ }^{49} \mathrm{PN}, 1 / 4 / 1921$.

${ }^{50} E S, 4 / 2 / 1921$.

${ }^{51}$ Las resoluciones del Congreso se encuentran en Abad de Santillán (2005: 259-265).

${ }^{52} P N, 5 / 9 / 1920$.
} 
gremio de Mozos y Anexos por su parte, nombró un delegado para asistir al congreso de la FORA Comunista. ${ }^{53}$

La participación en el Congreso regional debió influir para que la FOLC, mediante circular, convocara a los gremios adheridos para que discutieran en asamblea la adhesión a la FORA Comunista. Para el mes de diciembre de 1920, los miembros de $P N$ interpretaron que la propuesta había sido recibida con mucha simpatía por gran parte de los sindicatos y sociedades, a excepción de los obreros gráficos. ${ }^{54}$ Los pensanovistas aprovecharon para afirmar que la afiliación a una federación comunista no significaría una suscripción a una "tiranía ideológica" y desplegaron una serie de observaciones hacia los integrantes de la Sociedad de Artes Gráficas, quienes fueron una pieza clave para la concreción de la FOLC. De ellos habían provenido las bases, principios y finalidades anárquicas discutidas en el congreso que posteriormente se convirtieron en gran parte de la Carta Orgánica de la FOLC. Otra de las observaciones se relacionaba con que la afiliación a la regional comunista no implicaba que los asociados tuvieran que sumarse obligatoriamente a las filas de la anarquía. ${ }^{55}$

Por lo tanto, para los pensanovistas la posición de adherir a la central sindical ácrata no representaba una ruptura de los principios de la carta orgánica de la FOLC. Podía producirse la afiliación sin que los gremios perdieran su libertad y autonomía. Se ponderaba la acción conjunta y mancomunada con el resto de los sindicatos del país nucleados en la FORA V.

La posición asumida por el gremio de artes gráficas obligó a los miembros de PN y al CF de la FOLC a expresar con mayor justeza la afiliación ya que cuatro meses después de iniciada la convocatoria, sólo cuatro gremios (panaderos, mozos y anexos, repartidores de pan y tranviarios) habían resuelto en sus respectivas asambleas apoyar la adhesión a la FORA V. ${ }^{56}$

Durante varios meses la FOLC propició la adhesión de los gremios afiliados a la FORA V aduciendo que se trataba de un paso natural debido a la orientación comunista anárquica asumida por la federación desde su fundación. Se esgrimieron dos motivos fundamentales con la clara intención de movilizar a los sindicatos afiliados, el primero tendió a resaltar la importancia de integrarse al conjunto de organizaciones del país que asumían a la FORA V como la única

\footnotetext{
53 Este gremio aclaraba que participaron del congreso enviando delegados en carácter de organización autónoma; $L V G$, 5/9/1920. Para el mes de noviembre, luego de haber participado activamente del Congreso Regional, tomaron la determinación de adherirse a dicha central; LVG, 5/11/1920.

${ }^{54} \mathrm{El}$ argumento que esgrimían los obreros gráficos era que afiliarse a la federación comunista implicaba a los miembros del gremio ser anarquistas, aunque éstos no quisieran; $P N, 5 / 12 / 1920$.

${ }^{55}$ PN, 5/12/1920.

${ }^{56} \mathrm{PN}, 1 / 4 / 1921$.
} 
central revolucionaria y la segunda se relacionaba con la premura del contexto, en el que esa adhesión resultaba urgente ante lo que consideraron un avance conjunto de las fuerzas antirrevolucionarias. Así, proponían:

“...mancomunar en un organismo nacional a todas las fuerzas revolucionarias de la región, para oponerse frente a todas las fuerzas anti revolucionarias conglomeradas de las organizaciones amarillas en los partidos políticos obreristas y en la Liga Patriótica Argentina". ${ }^{77}$

No fue hasta el 1 de junio de 1921 que $P N$ dio a conocer la afiliación definitiva de la FOLC a la FORA Comunista; sin muchas explicaciones lo anunciaron como una lógica medida adoptada por mayoría entre los gremios adherentes dada la coincidencia finalista incluida en las cartas orgánicas de las federaciones local y regional.

Mientras que, por un lado, una decena de gremios del ámbito capitalino aunaron posiciones doctrinarias y adhirieron a la organización regional quintista, por otro, entre enero y febrero de 1921 se realizó en la ciudad de La Plata el XI Congreso de la FORA novenaria. ${ }^{58}$ Antes de que se realizara, Senra Pacheco envió cartas a delegados de diversos gremios de la provincia invitándolos al mismo. En Mendoza, la organización de este congreso no se dio sin disputas entre sindicatos y al interior de ellos. Un ejemplo de esta situación se dio en la Sociedad Cosmopolita de Obreros de Villa Maipú, en donde el delegado elegido para asistir al congreso fue fuertemente criticado por sus propuestas al mismo. ${ }^{59}$ Por lo tanto, la gravitación de la FORA IX se encontraba activa entre los gremios de la campaña, situación que como veremos a continuación jugó un rol importante durante este período del movimiento obrero provincial.

\section{Una nueva derrota obrera y el llamado a la unidad}

Entre los meses de marzo y abril (época de cosecha de la vid) de 1921 se habían desarrollado importantes conflictos en la provincia. Una huelga vitivinícola se destacó por ser muy dura y sangrienta. Los trabajadores vitivinícolas divididos por departamentos llevaron adelante este conflicto por mejoras en sus condiciones de vida y de trabajo, resultando los obreros de Maipú muy afectados debido a la represión, cierre de locales, incendios por parte de las fuerzas represivas, el asesinato de un huelguista por parte del ejército en la bodega Giol y más de 30 heridos. En Godoy Cruz, se dio una situación similar.

\footnotetext{
${ }^{57} P N, 1 / 6 / 1921$.

${ }^{58}$ Para ampliar el desarrollo de este congreso regional, véase Marotta T. II (1961) y T. III (1971).

${ }^{59}$ PN, 1/2/1921.
} 
Sin embargo, en San Martín la huelga fue exitosa y las empresas aceptaron todo el pliego de condiciones. En el resto de los departamentos la lucha terminó en una derrota para los trabajadores. Si bien los anarquistas tuvieron algún rol de dirección en esta huelga, el sindicalismo seguía tratando de hacer pie en el movimiento obrero mendocino y en esta huelga tuvo un acercamiento. Los socialistas, quizás dando cuenta de sus simpatías al sindicalismo nuevamente, publicaron una carta de la FORA IX (firmada por Senra Pacheco) en donde la central sindicalista se declaraba en solidaridad con la huelga de los obreros vitivinícolas. ${ }^{60}$ Este hecho volvió a poner sobre la mesa el debate de tendencias entre las izquierdas mendocinas $\mathrm{y}$, de manera similar a la huelga de maestras de 1919, determinó la organización que se darían los trabajadores mendocinos posteriormente.

Esta nueva derrota marcó un tiempo propicio para que desde $P N$ se realizara un breve balance sobre la actuación de la FOLC hasta el momento. En primera instancia, dieron cuenta de los persistentes intentos de desorganización llevados a adelante por el Partido Socialista. ${ }^{61}$ A pesar de ello, planteaban que la labor llevada a cabo por la FOLC había logrado formar una Sociedad de Conductores de Vehículos netamente obrera (ya que anteriormente participaban patrones), se había constituido la sociedad de resistencia de choferes, se organizaron sindicatos en el departamento de Rivadavia, entre otras acciones. Además, en gran parte respondiendo a una nota de $E S^{62}$ en la que responsabilizaban a la federación de la derrota a partir de los métodos de lucha adoptados, de abandono y falta de dirección seria, aclaraba que:

“...en ningún punto ha fomentado huelgas ni ha predicado la violencia, como pueden atestiguarlo los mismos sindicatos. No ha arrastrado a ningún gremio a la huelga [...]. Este consejo federal no tiene culpa alguna de la pérdida de los movimientos huelguistas" ${ }^{63}$

Esta afirmación muestra hasta qué punto estaba siendo cuestionado en la provincia el uso de la huelga en las disputas obreros-patronales así como la

\footnotetext{
${ }^{60} E S, 25 / 3 / 1921$.

${ }^{61} \mathrm{PN}$ denunciaba que los socialistas combatían persistentemente a la Federación, propiciando la disolución de algunos sindicatos cuyas organizaciones eran endebles (como el de albañiles y carpinteros por ejemplo) o difundiendo campañas ignominiosas para sembrar la desconfianza de los gremios adherentes; $P N, 1 / 4 / 1921$.

62 “Todos los sindicatos adheridos a la FOLC, [...] muchos de ellos no tienen de sindicatos nada más que el sello, cuando se han embarcado en un movimiento de huelga, [...] han sentido en toda su intensidad las consecuencias del fracaso, porque cuando se hacía imprescindible la intervención de los señores anarquistas dirigentes, éstos, prudentemente escurrían el bulto [...] y que los crédulos huelguistas se las arreglaran como pudieran"; $E S, 25 / 3 / 1921$.

${ }^{63} \mathrm{PN}, 1 / 4 / 1921$.
} 
virulencia con la cual se daban los debates entre las tendencias de izquierda mendocina. ${ }^{64}$

A poco tiempo de finalizada la huelga vitivinícola, la FOLC comenzó a convocar vehementemente a la realización de un Congreso Obrero. Si bien, nuevamente el objetivo principal era constituir la FOPM, la dura derrota sufrida por los obreros de bodega y viñedos hizo más urgente la necesidad de organizar a las y los trabajadores de la provincia en sociedades de resistencia.

“El doloroso fracaso sufrido [...] durante el conflicto de marzo último debe ser una lección provechosa [...]. Débese recordar que por la falta de organización, mientras en Maipú y Godoy Cruz se luchaba valientemente por arrancar a la fiera capitalista un mendrugo más de alimento, acudían a Las Heras, Guaymallén y otros departamentos grandes cantidades de trabajadores que, engañados o por espíritu de traición, se prestaban para aplastar la lucha de sus valientes hermanos, reemplazándolos en el trabajo. Todo esto se habría evitado si en cada departamento o distrito de importancia se hubiera contado con sindicatos [...]. La realización de un congreso obrero provincial se impone como una necesidad intensamente sentida. Todos los gremios de la provincia y en especial los del campo más esquilmados y castigados por su misma falta de preparación deben alistarse para asistir al congreso meditando bien los temas a discutir y no perdiendo de vista la finalidad que deben perseguir los sindicatos obreros modernos, que es la abolición del capitalismo y de todas las trabas que forman la cadena de nuestra esclavitud". ${ }^{65}$

En un marco de profundo decaimiento en las organizaciones obreras diagnosticado por los ácratas pensanovistas- lanzaron impugnaciones a la actitud poco revolucionaria asumida por varios de los militantes de la FOLC, quienes no lograban advertir, primero y, revertir después, la gravedad de la situación. Asimismo, desde la federación, se iniciaron tratativas para el envío de una delegación de la FORA Comunista para hacer una gran campaña de

\footnotetext{
${ }^{64}$ Estos debates fueron haciéndose cada vez más violentos, con acusaciones de ambos lados e incluso por medio de otras vías, como el boicot de los anarquistas hacia la cooperativa socialista "La Lucha". Es importante señalar que en estas disputas resaltaban los fuertes personalismos de algunos militantes de las corrientes, lo cual se puede apreciar en la mayoría de las notas de las dos prensas, destacándose dentro de las filas del anarquismo los dirigentes Gris y Pruneda y en el socialismo Fortes, Morey, Castromán, Grant Carrión, entre otros.

${ }^{65}$ PN, 15/5/1921.
} 
agremiación y moralizar a los federados, cuestión que se concretó con la llegada de dos delegados pertenecientes a la FORA V. ${ }^{66}$

En un contexto signado por una nueva derrota obrera, avances escuetos en cuanto a organización se refiere, un diagnóstico poco alentador respecto del activismo, y apoyados en los impulsos propiciados por la FORA V, la FOLC emprendió la organización de un nuevo congreso mediante el cual intentarían conseguir la unificación del movimiento obrero provincial. ${ }^{67}$ Por su parte, los socialistas inicialmente saludaron la convocatoria al Congreso Obrero provincial, sobre todo en lo relativo al punto de la unificación gremial en una federación provincial con orientación autónoma, tal como había sido realizada la convocatoria desde la circular elaborada por la comisión organizadora. Consideraron que sería un momento propicio para avalar o rectificar errores y cambiar derroteros decididos democráticamente mediante la participación y el voto o censura a la gestión del organismo central. Además, los socialistas convocaron a la participación gremial para que, con su presencia, criticaran y analizaran las acciones que deberían llevarse a cabo para agrupar a los trabajadores mendocinos bajo una nueva dirección que pudiera llevarlos a la victoria en sus conflictos periódicos. Sin embargo, advertían que a él, deberían concurrir no sólo los pocos gremios de la FOLC sino el conjunto de los trabajadores mendocinos. ${ }^{68}$

\section{El Congreso Obrero Provincial y la refundación de la FOPM}

La apertura del Congreso (17 de septiembre de 1921) fue acompañada por los delegados pertenecientes a dos federaciones -FORA V y un delegado de la FOP de San Juan. Los gremios provinciales concurrentes fueron los siguientes: Albañiles, Artes Gráficas, Carpinteros, Constructores de Vehículos y Carros, Ebanistas, Electricistas, Ferroviarios (Secciones de Tracción, Talleres y Sindicato de FCP), Mecánicos, Panaderos y Toneleros (dos secciones); Servicios públicos y privados: Cocineros, Cocheros, Chauffers, Federación Postal y Telegráfica, Mozos, Repartidores de pan y Tranviarios; Sociedades: Cosmopolita de Godoy Cruz, de Maipú, de San Martín. ${ }^{69}$

El clima reinante fue tenso desde el comienzo. Entre los delegados figuraban militantes pertenecientes a distintas corrientes ideológicas y políticas. Sobresalieron por su filiación anarquista los representantes de los gremios de Mozos y anexos, Panaderos, Repartidores de pan, Chauffers, Tranviarios y

\footnotetext{
${ }^{66} P N, 1 / 8 / 1921$.

${ }^{67} P N, 15 / 8 / 1921$. Se corresponde esta publicación de $P N$ con el último número disponible hasta el momento.

${ }^{68} E S, 16 / 9 / 1921$.

${ }^{69} E S, 23 / 9 / 1921$.
} 
Cosmopolita de Godoy Cruz; por el socialismo los Gráficos y Cosmopolita de Maipú; y autónomos o presumiblemente sindicalistas los ferroviarios, carpinteros, viticultores, entre otros. La Comisión de Poderes, encargada de estudiar las credenciales presentadas por los delegados de cada uno de los gremios participantes, estuvo compuesta por una considerable mayoría de representantes pertenecientes a la tendencia anarquista. En su informe, rechazaba a varios de los delegados pertenecientes al PS o de extracción sindicalista. ${ }^{70}$ La discusión se extendió entre los representantes de los gremios rechazados quienes defendieron su participación en el Congreso aduciendo el incumplimiento de la prescindencia ideológica con la que se había convocado al congreso, inacción y falta de solidaridad por parte de la FOLC en los conflictos obreros, desvirtualización del sindicalismo con fines personalistas, sectarios y cacicazgo ejercido por el CF. Finalmente, se ratificaron los rechazos de las credenciales mediante votación, siendo rectificada solo la de carpinteros. Ese día se levantó la sesión retirándose, además de los delegados rechazados (Gráficos y Albañiles), los de la Federación Postal, Constructores de Vehículos, Ferroviarios, Viticultores de Godoy Cruz y Cosmopolita de Maipú. ${ }^{71}$

La tercera sesión del Congreso estuvo signada por la moción presentada por gremios pertenecientes a la FOLC para adherir la Federación a la FORA Comunista. Después de varias intervenciones realizadas por los delegados pertenecientes a las diferentes tendencias, y ante una salida que no buscó el consenso como solución, se resolvió la adhesión a la FORA Comunista mediante votación por mayoría simple. ${ }^{72} \mathrm{El}$ gremio de los carpinteros dio por finalizada su participación en el congreso.

A la siguiente sesión, solo asistieron "los complotados" y "las visitas llegadas de Buenos Aires y San Juan", siendo presidida por el delegado de la Federación sanjuanina, según indicaron los socialistas. ${ }^{73}$ La quinta y última sesión transcurrió "nuevamente en familia". En esta última jornada, se decidió la conformación del Consejo Local (FOLC) y Provincial (FOPM). Para finalizar se aprobó "una moción protestando de la tiranía de Lenin". ${ }^{74}$ Este último

\footnotetext{
${ }^{70}$ Los rechazos recayeron sobre los gremios de: Ferroviarios y Sociedad de Artes Gráficas, fundamentando que su delegado titular, Mariano Rivas era un militante activo del Partido Socialista y, por lo tanto, considerado "político". Con argumentos similares se rechazó la credencial de Monforte (delegado por la Sociedad Cosmopolita de Maipú) y, finalmente, fueron observadas las credenciales del gremio de los Carpinteros por no reunir el número suficiente de agremiados y la de los Albañiles, por estar desorganizados; ES, 23/9/1921.

${ }^{71}$ ES, 30/9/1921.

${ }^{72}$ Para los socialistas se trató de un complot llevado a cabo por los principales gremios que sostuvieron los principios de la FOLC en el Congreso. Los sindicado señalados fueron: Panaderos, Tranviarios, Mozos, Fideeros y Cosmopolita de Godoy Cruz; ES, 14/10/1921.

${ }^{73} E S, 14 / 10 / 1921$.

${ }^{74} E S, 14 / 10 / 1921$.
} 
elemento muestra también el cambio de orientación de la FORA Comunista o quintista, la cual para ese momento ya tenía una posición antagónica respecto a la Revolución Rusa.

En el segundo número de Surco Proletario (órgano oficial de la FOPM adherida a la FORA Comunista) ${ }^{75}$ se dio a conocer el Pacto de Solidaridad y la Carta Orgánica votada en el Congreso y aprobada el día 19 de septiembre.

Del pacto, se desprende un marcado clasismo y una posición antigubernamental. Bregaron por el cumplimiento del axioma de la Primera Internacional, "la emancipación de los trabajadores debe ser obra de los trabajadores mismos", en cuyo núcleo de acción proletaria primó la formación de sindicatos por oficio, ligados por pactos recíprocos y solidarios, sin menoscabar la autonomía de los mismos, permitiendo la diversidad de ideas sociales.

La Federación naciente, en línea con los principios de la FORA V, propendió a la organización de la clase obrera en sociedades de oficio con el objeto de mejorar la situación económica, moral e intelectual de sus afiliados valiéndose de la acción directa como principal método de lucha. A fin de que los sindicatos no detuviesen su acción en la conquista de medidas inmediatas, el Congreso aprobó y recomendó a las sociedades adheridas, "la propaganda más amplia en el sentido de inculcar a la masa trabajadora en los principios del Comunismo Anárquico que ha de llevar a la humanidad a su emancipación completa". ${ }^{76}$ Además, propició la práctica del principio de solidaridad estrechando relaciones con todas las organizaciones y federaciones obreras comarcales, locales, regionales e internacionales que persiguieran el mismo fin.

En cuanto a la organización de la Federación, se creaba un Consejo Provincial compuesto por nueve delegados de las sociedades adheridas quienes se encargaban de elegir al secretario general, secretario de actas, tesorero y seis vocales. Duraban un año en el desempeño de sus funciones con derecho a reelección y sus mandatos eran revocables por decisión de los delegados sindicales. Taxativamente se establecieron límites a la composición de las comisiones administrativas o representativas de los gremios. Capataces, pequeños empresarios, trabajadores que tuvieran una notoria actuación política no podrían ser parte de las comisiones y aquellos que ejercieran cargos políticos (tales como concejal, diputado o empleados superiores de la administración) directamente debían ser excluidos de sus respectivos sindicatos.

\footnotetext{
${ }^{75}$ Hasta el momento solo hemos podido dar con 4 números (núm. 2, 3, 4 y 5). Los ejemplares disponibles abarcan un periodo entre octubre de 1922 y abril de 1923. El lema de este órgano fue: "Hermanos son los déspotas y los explotadores del mundo; y unidos están por el oro y el poder. Hermanos somos también los trabajadores del mundo y solo falta el ideal que nos una contra nuestros tiranos. ¡Trabajemos para que ese ideal sea el comunismo anárquico!".

${ }^{76}$ Surco Proletario (SP), núm. 2, octubre de 1922.
} 
Para el socialismo local, la impresión general fue decididamente negativa. Destacaron que el Congreso había sido un fracaso rotundo, sobre todo en lo concerniente a los alcances de la unidad lograda para los gremios mendocinos. Denunciaron que las sesiones habían sido influenciadas por una tendencia "exclusivista" y asesorada por delegados de la Capital Federal pertenecientes a la FORA Comunista. También repararon en el "sectarismo" evidenciado en el rechazo a las credenciales de entidades gremiales de importante calibre y probadas en la lucha y en el rechazo de aquellos delegados que profesaban ideas políticas, sobre todo las socialistas, sin constatar si eran legítimos representantes de los sindicatos. Finalizaban alegando que se había desperdiciado un momento oportuno para aunar la orientación general de los sindicatos provinciales ya que numerosas organizaciones pertenecientes al ámbito rural, como así también importantes gremios de la capital provincial habían sido apartados de ese proceso, lo que hubiera fortalecido la organización del movimiento obrero provincial. ${ }^{77}$ Este balance realizado por los socialistas los habilitaba a desconocer a la nueva Federación surgida del "congreso anarquista". Por ende, llamaron a la refundación de la antigua FOPM surgida tres años antes. ${ }^{78}$

Pasado un año de la conformación de la FOPM, un informe del Consejo Provincial saliente fue publicado en SP. En él referían a un estado de situación "caótica" de las organizaciones obreras de la provincia, principalmente debido a "la indiferencia suicida de la inmensa mayoría del proletariado rural". Si bien aseveraban que la influencia de socialistas y sindicalistas entre los gremios de la campaña era "nula" y pese a que los mayores esfuerzos de la nueva FOPM estuvieron avocados a organizar a ese sector de trabajadores, los resultados habían sido exiguos. Increpaban al proletariado "que trabaja en los campos despierte y sacuda esa indiferencia hacia la organización, causa por la cual vive en una condición deprimente y vergonzosa, pues el salario que percibe en cambio de su rudo trabajar, es denigrante, y por ello vemos que vegetan en medio de la mayor miseria económica y moral". La causal de esta situación la relacionaban con la "ignorancia característica en los campos", que permitía "a los explotadores sacar el máximo provecho con la mínima retribución”. ${ }^{79}$

En el balance político realizado por el Consejo Provincial saliente se insistía en la realización de mitines, conferencias y propaganda escrita como los

\footnotetext{
${ }^{77} E S, 23$ y 30/9/1921.

${ }^{78} E S, 7 / 10 / 1921$. El llamado realizado por el socialismo a la conformación de una federación paralela e integrada por gremios autónomos encontró eco entre los Carpinteros y Ebanistas que resolvieron enviar una circular a los sindicatos de la provincia para la celebración de un próximo Congreso, "sin sectarismos de ninguna clase". En la misma información lanzaban un manifiesto a los obreros organizados, explicando los por qué de la separación de la Federación Obrera Local Comunista; ES, 21/10/1921.

${ }^{79}$ SP, núm. 3, noviembre de 1922.
} 
recursos más frecuentes empleados durante su dirección. Según analizaban, los primeros fueron concretados con mayor énfasis en los departamentos en los que primaba la composición obrera rural. Las giras de propaganda fueron por mucho la más ponderada de las acciones ya que, según el informe, habían producido los mejores resultados en términos organizativos. Entre febrero y mayo de 1922, el Consejo emprendió giras acompañadas por un delegado de la FORA V para reorganizar a los sindicatos más debilitados. La participación de los delegados de la central regional también se hizo presente para contrarrestar los efectos de la propaganda desplegada por la naciente Unión Sindical Argentina. También atestiguaban haber podido reorganizar la FOL de San Rafael.

Para finalizar, los gremios intervinientes en la FOPM quintista entre 1922 y 1923 -consignados en los números disponibles de $S P$ - nos sugieren que ${ }^{80}$ los gremios de la capital mantuvieron una destacable estabilidad numérica durante el proceso en estudio (aproximadamente una decena). La Federación Local departamental más consolidada fue la de San Rafael, cuya existencia se remontaba al año 1920. La expansión territorial hacia el resto de los departamentos aparece como el diferencial más importante en términos comparativos ya que connota ciertos avances organizacionales en los gremios denominados de la campaña.

\section{Palabras finales}

Este trabajo es una primera aproximación a la reconstrucción de la historia del movimiento obrero mendocino de la década del '20. A lo largo del mismo hemos podido observar los vaivenes de las organizaciones obreras más importantes de la provincia. Esto, desde ya, no está visto por fuera de la situación nacional, en la cual, como planteamos previamente, se desarrollaba un proceso de división dentro de las izquierdas argentinas, en los gremios y federaciones. Además, asistimos a un proceso de huelgas y conflictos de gran envergadura en la historia argentina, del que Mendoza no estuvo exenta.

En este sentido podemos destacar hasta qué punto las huelgas determinaron el auge y caída de las organizaciones en la provincia. Por un lado, la segunda huelga general convocada por la FOPM en solidaridad con las

\footnotetext{
${ }^{80}$ La composición gremial de la FOLC en la ciudad de Mendoza era la siguiente: Panaderos, Tranviarios, Repartidores de Pan, Cocineros, Chauffeurs, Conductores de Coches, Mozos, y Unión Servicio Doméstico. En la FOL de San Rafael: Albañiles, Gastronómicos y Anexos, Unión General de Obreros, Oficios Varios y Panaderos; Godoy Cruz: Molineros y Cerveceros; Gral. Benegas: Cerveceros y Anexos). En San Martín: Obreros Unidos. Rivadavia: Panaderos. Villa Nueva: Oficios Varios. Rodeo de la Cruz: Obreros Unidos. Luján: Unión Obrera. San José: Unión Obrera. Maipú Toneleros (Pereyra, 2020).
} 
maestras de 1919, determinó en gran medida el vaciamiento y caída de la Federación. Esto generó diversas iniciativas organizativas a fin de refundar esta federación (Congreso Obrero de julio de 1920, creación de la FOLC, intentos de unificación con las federaciones regionales). Por otro lado, la importante huelga vitivinícola de marzo-abril de 1921 fue la que puso en debate nuevamente la unificación del movimiento obrero mendocino, generando el Congreso Obrero de septiembre de 1921 del que surgió una nueva FOPM afiliada a la FORA V.

Sin embargo, este proceso no puede ser abordado sin tomar en cuenta el rol que cumplieron las izquierdas en la provincia. Por un lado, el sindicalismo (FORA IX) quedó totalmente desacreditado por la propia FOPM, que caracterizó -conjuntamente con el PS y anarquistas- de haber traicionado al movimiento obrero local ante lo actuado por los principales referentes de la central nacional durante el duro conflicto de 1919. Absolutamente desprestigiados, perdieron la dirección de la federación provincial y su influencia quedó circunscripta a muy pocos gremios de la capital, manteniendo cierta injerencia en los de la campaña. Luego de la fuerte derrota, se abrió un proceso progresivo de vaciamiento gremial y el declive definitivo de la FOPM ocurrió cuando la dirección estaba en manos de importantes cuadros obreros del socialismo. En breve se encontraron eclipsados por la tendencia anarquista que aprovechó la dispersión de ambas tendencias - sindicalista y socialista- para tomar la iniciativa y dirigir la reorganización de los trabajadores mendocinos.

El Partido Socialista mendocino, si bien en sus principios continuó defendiendo la autonomía sindical y la no adscripción a tendencia obrera ninguna, durante el proceso estudiado tuvo un rol destacado, disputando la orientación del movimiento obrero local. Hemos enunciado el rol activo que asumió durante los congresos. Para el de julio de 1920 propició la organización de gremios autónomos y ante el avance de los anarquistas, desmovilizaron a los gremios de la campaña, logrando infringirle una importante herida al anarquismo que había logrado dirigir la convocatoria al Congreso obrero. En ese momento el PS y el sindicalismo aunaron posiciones. Aún así quedó conformada la FOLC. Luego, en el segundo Congreso, la tendencia socialista tomó la iniciativa y se trabó en una dura lucha política contra la tendencia quintista que finalmente se impuso en la conformación de la nueva FOPM en 1921. El desconocimiento de esta nueva federación obrera provincial y el llamado a conformar una paralela, muestra hasta qué punto los socialistas intentaron direccionar a los gremios autónomos y sindicalistas hacia nuevos horizontes y bajo su égida, a pesar de la prescindencia político-gremial enunciada en sus plataformas.

Es necesario destacar el rol y la iniciativa del anarquismo en la provincia en un proceso en el que la correlación de fuerzas le resultó favorable, ya que el sindicalismo había quedado desprestigiado y el socialismo tomó una posición ambigua. Primero lograron una importante influencia en la Comisión Pro 
Congreso Obrero y luego dirigieron efectivamente dos federaciones entre 1920 y 1922. La FOLC marcó el inicio de la hegemonía ácrata que decantaría con mayor fuerza un año después en la refundación de la FOPM, bajo la efectiva orientación quintista. Merece la pena destacar que estos avances organizativos fueron logrados durante un momento de gran reflujo del movimiento obrero provincial en el que también tuvo roles de dirección en huelgas muy importantes y en donde, además, tuvieron como contrincantes a los socialistas que trataron de boicotear cada iniciativa ácrata.

Hemos mostrado cómo el movimiento obrero provincial se encontraba integrado al nacional, sobre todo a través de las dos federaciones regionales más representativas. La presencia de la FORA $V$, a través del envío de delegados/as en forma casi permanente y la participación en el congreso extraordinario de 1920, implicaron acciones muy ponderadas por los libertarios mendocinos (propaganda por la idea, organización y fundación de gremios; y moralización de los federados locales en momentos de decaimiento). Si bien los anarquistas locales tomaron la iniciativa organizativa, sus definiciones iniciales como "sindicalistas revolucionarios con miras al comunismo anárquico" fueron entroncando cada vez más con los axiomas del quintismo nacional; mismo caso ocurrió con las cartas orgánicas de las nacientes federaciones (Local y Provincial). Al contrario, palpable fue la ausencia de delegados regionales sindicalistas durante todo el proceso; a pesar de su evidente relación con algunos gremios provinciales, su contacto fue a través de cartas o solicitadas publicadas en los diarios.

Sin embargo, más allá de las iniciativas de las diversas corrientes que se disputaban la dirección de los trabajadores, éstos no pudieron revertir el retroceso existente en el movimiento obrero provincial, que pasó de estar organizado en una federación de más de 50 gremios en 1919, a una que agrupaba muy pocos sindicatos. Más allá de este reflujo, es innegable que el anarquismo fue uno de los mayores y más interesados organizadores del proletariado provincial, tratando de inculcar su ideología y métodos, "libres de prejuicios, libres de mentores, dueños de sí mismos. ¿Por qué medios? Por la organización gremial". ${ }^{81}$

\section{Referencias bibliográficas}

Abad de Santillán, D. (2005). La FORA. Anarres.

Andújar, A. y Lichtmajer, L. (2021). Oportunidades y desafíos de la historia local: algunas reflexiones desde un campo en expansión. Anuario del Instituto de Historia Argentina, 21 (1). [en línea] https://doi.org/10.24215/2314257Xe132

\footnotetext{
${ }^{81} P N, 4 / 7 / 1920$.
} 
Aquino, C. (2015). Bajo la influencia de la Revolución Rusa. La Federación de Agrupaciones Sindicalistas Revolucionarias a través de La Batalla Sindicalista 1920/1923. Archivos de historia del movimiento obrero y la izquierda, (7), 123-142.

Aquino, C. (2017). Las disputas del sindicalismo revolucionario por los gremios ferroviarios durante la primera posguerra. Archivos de historia del movimiento obrero y la izquierda, (10), 75-94.

Anapios, L. (2007). Compañeros, adversarios y enemigos. Conflictos internos en el anarquismo argentino en la década del '20. Entrepasados, (32), 27-41.

Beigel, F. (2004). Entre el maray, la papeleta de conchabo y los derechos sociales: Los trabajadores en la Historia de Mendoza. En A. Roig (Comp.), Mendoza, cultura y economía (pp. 257-292). Caviar blue.

Becerra, M. (2019). Un cuarto propio: relaciones de género, amor y magisterio en la Argentina de inicios del siglo XX. Propuesta Educativa, (51), 42-60.

Belkin, A. (2015). La huelga general de enero de 1907 y las estrategias políticas de socialistas, anarquistas y sindicalistas revolucionarios. Estudios del Trabajo, (49), 31-58.

Belkin, A. (2018). Sindicalismo revolucionario y movimiento obrero en la Argentina: de la gestación en el Partido Socialista a la conquista de la FORA (1900-1915). Imago Mundi-Archivos.

Belkin, A. (2021). La huelga general de 1913: Crisis económica, represión estatal y división del movimiento obrero. Colección, 32 (2), 163-194.

Bohoslavsky, E. (Coord.). (2018). Dossier: Debates y conflictos de la historia regional en la Argentina actual. Quinto Sol, 22 (3), 1-51. [en línea] https://doi.org/10.19137/qs.v22i3.3337

Camarero, H. (2007). A la conquista de la clase obrera. Los comunistas y el mundo del trabajo en Argentina, 1920-1935. Siglo XXI.

Camarero, H. (2017). Tiempos rojos. El impacto de la Revolución rusa en la Argentina. Sudamericana

Carminatti, A. (2006). Enero de 1919, el conflicto social en Mendoza y Rosario. Escuela de Historia-UNR.

Caruso, L. (2016). "El gran barco: el sindicalismo revolucionario argentino a través de la obra de Julio Arraga". Izquierdas, 1-25.

Cerdá, J. M. (2006). Mercado de trabajo y condiciones de vida en Mendoza a comienzos del siglo XX.Mundo Agrario, 6(12). [en línea] https://www.memoria.fahce.unlp.edu.ar/art revistas/pr.523/pr.523.pdf

Díaz, H. (2014). Las giras sindicales como instrumento de construcción del movimiento obrero. La FORA en Entre Ríos (1918-1921). Historia Regional (32), 89-107. 
De la Vega, J. (1997). Mendoza 1919: „Huelga! El nacimiento de la sindicalización del magisterio mendocino. Ediciones culturales de Mendoza.

Falcón, R. y Montserrat, A. (2000). Estado, empresas trabajadores y sindicatos. En R. Falcón (Dir.), Nueva Historia Argentina T. 6. Democracia, conflicto social y renovación de ideas (1916-1930) (pp.151-195). Sudamericana.

Iñigo Carrera, N. (2004). La estrategia de la clase obrera 1936. Ediciones Madres de Plaza de Mayo.

Iñigo Carrera, N. (2017). La otra estrategia. La voluntad revolucionaria (1930-1935). Imago Mundi.

Iñigo Carrera, N. (2019). Estrategias de la clase obrera en los orígenes del peronismo. EUDEM y Grupo Editor Universitario.

Latorre Carabelli, M. (2019). Entre la escuela y la prensa. Primeras experiencias de organización sindical docente en Mendoza (1919). Prohistoria, (32), 97-126.

Luis, N. (2017). Una pionera legislación social: La sanción de leyes de regulación laboral en 1918 en Mendoza, Argentina. Cuadernos Americanos Nueva Época, (160), 185-217.

Leyes, R. (2009). La estrategia de sindicalización de la FORA del IXo en el oriente entrerriano (1917-1921). Revista del Programa de Investigaciones sobre Conflicto Social, $34-48$

Marianetti, B. (1970). Las luchas sociales en Mendoza. Cuyo.

Marianetti, B. (1972). Mendoza, la bien plantada. Sílaba.

Marotta, S. (1961 y 1971). El movimiento sindical argentino. T. I y II. Lacio.

Pereyra, M. (2020). Huelgas generales en Mendoza (Argentina) en 1927: Una aproximación a partir de las huelgas generales por Sacco y Vanzetti. Historia Regional (43), 1-15.

Richard-Jorba, R. (2007). Crisis Económicas y Conflictos Sociales en Mendoza en la Década de 1890 y los Primeros Años del Siglo XX. De la Resistencia Individual de los Trabajadores a la Acción Colectiva. Estudios Sociales, 32 (1), 3169.

Richard-Jorba, R. (2010a). Empresarios ricos, trabajadores pobres. Vitivinicultura y desarrollo capitalista en Mendoza (1850-1918). Prohistoria.

Richard-Jorba, R. (2010b). Conflictos sociales en Mendoza entre dos crisis, 18901916. Una larga lucha de los trabajadores por la conquista de sus derechos laborales. Prohistoria, (13), 51-80.

Richard-Jorba, R. (2011). Los gobiernos lencinistas en Mendoza. Salud pública y vivienda popular, 1918-1924. Avances del Cesor, (8), 31-62. 
Richard-Jorba, R. (2013a). Los frutos del viñedo deberían ser para todos. Depresión y resurrección de la vitivinicultura y aumento de la conflictividad social en Mendoza (Argentina), 1919-1920. Estudios Sociales, 45 (1), 71-101.

Richard-Jorba, R. (2013b). Somos el pueblo y la patria. El populismo lencinista en Mendoza frente al conflicto social y la prensa: discursos, representaciones y acciones, 1917-1919. Revista de Historia Americana y Argentina, 48 (1), 11-54.

Richard-Jorba, R. (2020). El movimiento obrero en Mendoza. Implosión, dispersión e intentos de reorganización 1918-1928. En P. Barrio y F. Rodríguez Vázquez (Coords.), Política, industria y servicios en Mendoza (1918-1943) (pp. 2977). TeseoPress.

Satlari, M. (2009). Organizaciones obreras en Mendoza en la primera etapa de los gobiernos radicales: anarquistas, sindicalistas y socialistas. La huelga de maestros de 1919 como factor aglutinante de las filiaciones de los obreros, Actas de las I Jornadas interdisciplinarias de Investigaciones Regionales. Enfoques para la historia, Mendoza, Argentina.

Satlari, M. (2011). Organizaciones obreras en Mendoza en el primer cuarto del siglo XX: Anarquistas, sindicalistas y socialistas. La huelga de maestros como factor aglutinante de las filiaciones de los obreros. En P. Núñez (Comp.), Miradas Transcordilleranas. Selección de trabajos del IX Congreso Argentino Chileno de Estudios Históricos e Integración Cultural (pp. 632-646). IIDyPCa, UNRNCONICET.

Satlari, M. (2013). Poesía anarquista en Mendoza para la Revolución Social (1918-1930). XIV Jornadas Interescuelas/Departamentos de Historia. Departamento de Historia de la Facultad de Filosofía y Letras. Mendoza, UNCuyo.

Silva, H. (2012). Enero de 1919: la Semana Trágica mendocina. La Hidra de Mil Cabezas (colección «naranja» Historia de los Movimientos Sociales).

Suriano, J. (2001). Anarquistas. Cultura y política libertaria en Buenos Aires, 18901910. Manantial. 